\title{
Explanatory Psychological Factors of Inconsistently Condom Use among Spanish University Students: Gender Differences
}

\author{
$<<$ Query: The distinction between surnames can be ambiguous, therefore to ensure accurate tagging for \\ indexing purposes online (eg for PubMed entries), please check that the highlighted surnames have been \\ correctly identified, that all names are in the correct order and spelt correctly. Ans: eruiz@uji.es: Data is \\ correctly.>>Estefanía Ruiz-Palomino ${ }^{1,{ }^{*}}$; María Dolores Gil-Llario ${ }^{2}$; Cristina Giménez-García ${ }^{1}$; \\ Rafael Ballester-Arnal ${ }^{1}$ \\ ${ }^{1}$ Universitat Jaume I (Spain) \\ ${ }^{2}$ Universitat de València (Spain) \\ *Correspondence concerning this article should be addressed to Estefanía Ruiz-Palomino. Universitat Jaume \\ I. Facultat de Ciències de la Salut. Departament de Psicologia Bàsica, Clinica i Psicobiologia. Av. Vicent Sos \\ Baynat, s/n. 12071 Castelló de la Plana (Spain). E-mail: eruiz@uji.es
}

\begin{abstract}
More than $50 \%$ of Spanish youth does not use of condoms correctly and consistently. University students are a particular population at high risk of the HIV infection, other STIs and unwanted pregnancies. The influence of psychological variables in using of condom is analyzed by gender and type of sexual relationship. A total of 256 females and 168 males were assessed $(M a g e=20.62$; $S D=2.16)$. A regression logistic analysis showed that sexual sensation seeking appears as an explanatory variable of inconsistently condom use in both females and males in vaginal intercourse, steady relationship intercourse and sex under the alcohol and other drugs effects (adjusted odds ratio between 1.095 and 1.124). Moreover, self-esteem appears as a risk factor and extraversion as a protective factor of use of condom in females. On the other hand, neuroticism reveals itself as a protective factor and fear of negative evaluation as a risk factor of use of condom in males. It is necessary to know the psychological mechanisms that underlie sexual risk behaviors for adapting interventions to individual and contextual characteristics.
\end{abstract}

Keywords: condom use; gender differences; sexual health promotion; type of relationships; youth

Data from the latest epidemiological surveillance reports show that Spanish youth are a priority group for the design and implementation of sexual health promotion strategies. In 2017, 3,381 new HIV diagnoses were notified, which represents an approximate rate of 7.26 per 100,000 population. The new HIV infections were mainly by sexual transmission (82.5\%), in men (63.9\%) and in people under 35 years old (47.3\%). Among women, heterosexual transmission constitutes the majority of new diagnoses (85.0\%) (Área de Vigilancia de VIH y Comportamientos de Riesgo, 2018). In the same year, a rate of 18.74 cases per 100,000 population of gonococcal infection, of 10.61 cases per 100,000 population of syphilis and of 7.6 cases per 100,000 population of Chlamydia trachomatis were reported. This sexually transmitted infections (STIs) were observed predominantly in men, except the Chlamydia trachomatis, and in people between 25 and 34 years old (Unidad de Vigilancia del VIH y Conductas de Riesgo, 2019). Finally, a total of 94,123 women made voluntary interruptions of pregnancy (VIP) during the same time period, mainly in people between 25 and 29 years 
old (Ministerio de Sanidad, Consumo y Bienestar Social, 2017). Spain appears in the highest positions in number of abortions (World Health Organization, 2019) and in syphilis cases (European Centre for Disease Prevention and Control, 2019c) reported in the EU/EEA countries. Moreover, it rank the ninth in gonorrhea cases (European Centre for Disease Prevention and Control, 2019b), the eleventh in Chlamydia infection cases (European Centre for Disease Prevention and Control, 2019a) and twelfth in new HIV diagnosis (European Centre for Disease Prevention and Control, 2018).

Although young university students have relatively good information related to sexual health, this population continue to be exposed to the risks involved in unsafe sexual behaviors (Bellis et al., 2008; Sánchez-Ojeda \& De Luna-Bertos, 2015; Ssewanyana et al., 2015). For example, Luengo-Arjona et al. (2007) found that only 3 out of 10 Spanish university students reported to use the condom in all their sexual intercourses. Moreover, more than $50 \%$ of young people of the different autonomous communities of Spain do not use the condom consistently in their sexual intercourses and less frequently with romantic relationships or under the influence of alcohol and other drugs (Ballester et al., 2009; Lameiras Fernández et al., 2008; Muñoz-Silva et al., 2009; Rojas-Murcia et al., 2015; Velo-Higueras et al., 2019). Due to the condom is the only preventive measure that, correctly and consistently used, prevents HIV infection, other STIs and unwanted pregnancies, it could be said that Spanish university students are a particular population at high risk.

Previous studies among Spanish university students have showed the influence of gender (Castro, 2016) and of other specific cognitive-social factors of the behavioral change theories as determinants of condom use in heterosexual relationships such as the HIV self-efficacy (Ballester-Arnal et al., 2013), attitudes towards condoms (Prat et al., 2016) or beliefs related vulnerability to AIDS (Rojas-Murcia et al., 2015). On the other hand, the association between condom use and different psychological factors in other countries have been well-documented in the scientific literature (Davis et al., 2014; MacDonald et al., 2016; Rodrigues et al., 2019). But the influence of predisposing factors as explanatory variables of condom use have been poor studied in Spain (Ballester-Arnal et al., 2017). Thus, the aim of the current study expands the previous understanding of condom use by examining the psychological factors influence by type of sexual practice and gender among sexual active university students.

\section{Method}

\section{Participants}

A total of 467 Spanish young people were assessed, a $91.2 \%$ of them self-identified as heterosexuals and $8.8 \%$ as lesbian, gay or bisexual. The exclusion criteria was self-identification as a non-heterosexual because the LGTB group was not sufficiently represented to performed differential analysis. The sample of the study was composed by 256 females and 168 males heterosexual Spanish young people were assessed $(M=$ 20.62; $S D=2.16$ ). All of them were studying at the university in different fields of study (Health Sciences: 20\%, Humanities and Social Sciences: 35.8\%; Legal and Economics Sciences: 25\%; and Technology and Experimental Sciences: $19.2 \%$ ) and lived in urban areas. Most of them self-identified as atheist or agnostic (47.8\%) and practicing Catholic (43.7\%).

\section{Instruments}

The following instruments were administered to all participants:

AIDS Prevention Questionnaire (Cuestionario de Prevención del Sida or CPS) (Gil-Llario et al., 2019). A 44-item questionnaire that assesses HIVIAIDS prevention as a multidimensional perspective. Some items 
of the Safe Sexual Behavior (SAS-B) factor were selected for the aim of this study. This factor is composed to a series of self-reported statements about frequency of condom use in different sexual practices (vaginal intercourse), types of partner (steady and occasional intercourse) and risk scenarios (sex under the alcohol and other drugs effects). The factor used has an internal consistency of .67.

Neo Personality Inventory Revised (NEO-PI-R) (Spanish adaptation by Cordero et al., 2008). A 240-item questionnaire that assesses the Big Five personality traits: Neuroticism (N), Extraversion (E), Openness to Experience (O), Agreeableness (A) and Conscientiousness (C). The domains of the version used has an internal consistency ranged from .83 to .92 .

Rosenberg Self-Esteem Scale (RSE) (Spanish adaptation by Martín-Albo et al., 2007). A 10-item selfreport that evaluates the individual self-esteem. The items can be answered on a scale from strongly agree to strongly disagree. The total score ranging from 0 to 30 points. The version used has an internal consistency of .88 .

Beck Depression Inventory II (BDI-II) (Spanish adaptation by Sanz et al., 2003). A 21-item that assesses clinical symptoms of the depression. Most of items can be answered on a four-point scale and the item $16 \mathrm{y}$ 18 on a seven-point scale. The total score ranging from 0 to 63 points and 14 points meaning mild depression. The version used has an internal consistency of 89.

Penn State Worry Questionnaire (PSWQ) (Experimental version by Castañeiras Gebrikian, 2001). A 16-item scale of trait anxiety adapted to assesses the general tendency to experience worry about health. The items can be answered on a scale from "not at all typical of me" to "very typical of me". The total score ranging from 16 to 80 points. The version used has an internal consistency of .90 .

Brief Fear of Negative Evaluation Scale (BFNE) (Spanish adaptation by Gallego et al., 2010). A 12-item that measure the degree to which a person fears being negatively evaluated by others. The items can be answered on a scale from not at all characteristic of me to extremely characteristic of me. The total score ranging from 12 to 60 points. The version used has an internal consistency of .90 .

Sexual Sensation Seeking Scale (SSSS) (Spanish adaptation by Ballester-Arnal et al., 2018). An 11-item that assesses the personality disposition to seek novel sensation on sexual context. The answers range from 1 not at all like me to 4 very much like me. The total score ranging from 11 to 44 points. The version used has an internal consistency of 82 .

Sexual Compulsivity Scale (SCS) (Spanish adaptation by Ballester-Arnal et al., 2013). A 10-item that assesses the personality disposition to sexual disinhibition and impulses. The answers range from not at all like me to very much like me. The total score ranging from 10 to 40 points. The version used has an internal consistency of .83.

Health Locus of Control Scale (HLC) (Wallston et al., 1976). An 11-item that measures individual's beliefs about perceived control about health. The answers range from strongly disagree to strongly agree. The total score ranging from 0 to 55 points, higher scores are indicatives of a tendency of internal health locus of control. The version used has an internal consistency ranged from .67 to .76 .

\section{Procedure}

It is an explanatory transversal design in which how predisposing traits influence on condom use was analyzed. Participants were recruited in university campuses of Valencian region in the awareness-raising activities in AIDS Day. Youth interested in participating in the study were provided more information via email or phone. Participants filled the questionnaires in pencil-and-paper, individually, in the university labs and supervised by the group members. The written consent of all participants was obtained. The procedure followed the ethical principles of APA and Helsinki Declaration and was approved by the Institutional Ethics 
Committee of the Universitat Jaume I.

\section{Analysis of Data}

Frequency analysis were performed to examine the prevalence of use of condom. Moreover, chi-squared test was used to evaluate whether there was a significant difference between frequencies of use of condom according to gender. Then, logistic regression was carried out to explain the relationship between a nominal dependent variable (use or non-use of condom) and the independent variables (predisposing factors) separately in females and males.

\section{Results}

\section{Description of Condom Use Frequencies and Analysis of Gender Differences}

A higher percentage of males than females do not use the condom consistently in all sexual situations evaluated. The percentage of non-use of condoms is higher when it is a steady relationship intercourse and lower when it is an occasional relationship intercourse, both in males and females. None of these differences according to gender was statistically significant (see Table 1).

Table 1. Condom Use Frequencies and Differences Analysis by Gender

\begin{tabular}{|c|c|c|c|c|c|}
\hline & $\%$ Males & $\%$ Females & $d f$ & $x^{2}$ & $p$ \\
\hline Vaginal sex & & & 1 & 0.083 & .832 \\
\hline Non-use consistently & $61.5 \%$ & $60.1 \%$ & & & \\
\hline Use consistently & $38.5 \%$ & $39.9 \%$ & & & \\
\hline Steady relationship intercourse & & & 1 & 1.212 & .310 \\
\hline Non-use consistently & $71.3 \%$ & $65.9 \%$ & & & \\
\hline Use consistently & $28.7 \%$ & $34.1 \%$ & & & \\
\hline Occasional relationship intercourse & & & 1 & 1.065 & .338 \\
\hline Non-use consistently & $40.3 \%$ & $34.5 \%$ & & & \\
\hline Use consistently & $59.7 \%$ & $65.5 \%$ & & & \\
\hline Sex under the alcohol and other drugs effects & & & 1 & 2.231 & .146 \\
\hline Non-use consistently & $59.6 \%$ & $51.3 \%$ & & & \\
\hline Use consistently & $40.4 \%$ & $48.7 \%$ & & & \\
\hline
\end{tabular}

\section{Explanatory Factors of Condom Use by Gender}

A regression logistic analysis for each sexual situation was performed in females (see Table 2) and males (see 
Table 3) separately. Hosmer-Lemeshow test did not obtain statistical significance, indicating goodness-of-fit of the models. Sexual sensation seeking appears as an explanatory variable of inconsistently condom use in both females and males in vaginal intercourse (females: $\beta=.114, p \leq .001$; males: $\beta=.102, p=.003$ ), steady relationship intercourse (females: $\beta=.094, p=.001$; males: $\beta=.117, p=.004$ ) and sex under the alcohol and other drugs effects (females: $\beta=.091, p=.003$; males: $\beta=.098, p=.006$ ). Moreover, in females, self-esteem $(\beta=.073, p=.050)$ reveals itself as a risk factor of use of condom with steady partners and extraversion $(\beta=$ $-.031, p=.049$ ) as a protective factor of use of condom in sexual intercourse under the alcohol or other drugs effects. The range of values of $\mathrm{R}$ square Naglekerke indicate that the proposed models accounts between the $7.7 \%$ and the $13.1 \%$ of the variance of the dependent variable in females. Specifically, sexual sensation seeking was associated with greater risk of inconsistently use of condom, but it multiplied only between 1.095 and 1.121 times the probability of non-use of condoms. In males, neuroticism ( $\beta=-.046, p=.018)$ appears as a protective factor of use of condom with steady partners and fear of negative evaluation $(\beta=.058, p=$ .014 ) as a risk factor of use of condom with occasional partners. The range of values of $\mathrm{R}$ square Naglekerke indicate that the proposed models accounts between the $8.1 \%$ and the $12 \%$ of the variance of the dependent variable in males. Specifically, sexual sensation seeking was associated with greater risk of inconsistently use of condom, but it multiplied only between 1.103 and 1.124 times the probability of non-use of condoms.

Table 2. Multiple Regression Logistic Analysis of the Condom Use in Females

\begin{tabular}{|c|c|c|c|c|c|c|c|c|}
\hline & $\boldsymbol{\beta}$ & $S E$ & Wald & df & $p$ & $O R$ & $95 \% \mathrm{Cl}$ & $\operatorname{adj} . R^{2}$ \\
\hline Condom use in vaginal sex & & & & & & & & .077 \\
\hline Sexual sensation seeking & .094 & .027 & 11.967 & 1 & .001 & 1.098 & $\begin{array}{r}{[1.041,} \\
1.158]\end{array}$ & \\
\hline Condom use in steady relationship intercourse & & & & & & & & 131 \\
\hline Sexual sensation seeking & .114 & .030 & 14.499 & 1 & $\begin{array}{c}\leq \\
.001\end{array}$ & 1.121 & $\begin{array}{r}{[1.057} \\
1.189]\end{array}$ & \\
\hline Self-esteem & .073 & .037 & 3.851 & 1 & .050 & 1.076 & $\begin{array}{r}{[1.000} \\
1.157]\end{array}$ & \\
\hline $\begin{array}{l}\text { Condom use in sex under the alcohol and other drugs } \\
\text { effects }\end{array}$ & & & & & & & & .081 \\
\hline Sexual sensation seeking & .091 & .031 & 8.823 & 1 & .003 & 1.095 & $\begin{array}{r}{[1.031} \\
1.163]\end{array}$ & \\
\hline Extraversion & - & .016 & 3.885 & 1 & .049 & .970 & $\begin{array}{l}{[.940} \\
1.000]\end{array}$ & \\
\hline
\end{tabular}

Table 3. Multiple Regression Logistic Analysis of the Condom Use in Males

\begin{tabular}{|c|c|c|c|c|c|c|c|c|}
\hline & $\beta$ & $S E$ & Wald & $d f$ & $p$ & OR & $95 \% \mathrm{Cl}$ & $\operatorname{adj} . R^{2}$ \\
\hline Condom use in vaginal sex & & & & & & & & .082 \\
\hline
\end{tabular}




\begin{tabular}{|c|c|c|c|c|c|c|c|c|}
\hline & $\boldsymbol{\beta}$ & SE & Wald & $d f$ & p & OR & $95 \% \mathrm{Cl}$ & $\operatorname{adj} . R^{2}$ \\
\hline Sexual sensation seeking & .102 & .035 & 8.571 & 1 & .003 & 1.108 & $\begin{array}{r}{[1.034} \\
1.186]\end{array}$ & \\
\hline Condom use in steady relationship intercourse & & & & & & & & .120 \\
\hline Sexual sensation seeking & .117 & .040 & 8.408 & 1 & .004 & 1.124 & $\begin{array}{r}{[1.039,} \\
1.217]\end{array}$ & \\
\hline Neuroticism & .046 & .019 & 5.599 & 1 & .018 & .955 & {$[.920, .992]$} & \\
\hline Condom use in occasional relationship intercourse & & & & & & & & .087 \\
\hline Fear of negative evaluation & .058 & .024 & 6.049 & 1 & .014 & 1.060 & $\begin{array}{r}{[1.012,} \\
1.110]\end{array}$ & \\
\hline $\begin{array}{l}\text { Condom use in sex under the alcohol and other drugs } \\
\text { effects }\end{array}$ & & & & & & & & .081 \\
\hline Sexual sensation seeking & .098 & .036 & 7.406 & 1 & .006 & 1.103 & $\begin{array}{r}{[1.028,} \\
1.184]\end{array}$ & \\
\hline
\end{tabular}

\section{Discussion}

Already in the Spanish Survey of Health and Sexual Habits of the year 2003, about $40 \%$ of Spanish young people between 18 and 29 years old did not always use condoms in their sexual relations during the last year (Instituto Nacional de Estadística, 2003). More than 15 years later, between $40 \%$ and $70 \%$ of university students evaluated in this study are at risk of unwanted pregnancies, HIV infection or other STIs. These data are confirmed in the bibliographic review carried out by Sánchez-Ojeda and Luna-Bertos in 2015 with a Spanish university population. These percentages are similar to those found in previous studies carried out with Spanish university students of the Valencian Community (Ballester et al., 2009), Catalonia (Prat et al., 2016), Madrid (Rojas-Murcia et al., 2015), Andalusia and Galicia (Lameiras Fernández et al., 2008).

The inconsistent use of condoms is greater in steady relationships, as is showed by Rojas-Murcia et al. (2015) in Spain or Ssewanyana et al. (2015) in other European countries. Generally, steady relationships have implicit a series of characteristics (affective commitment, security, trust, intimacy, etc.) that negatively influence the use of condoms, despite the fact that in many cases young people do not know the health status of their sexual partner, a phenomenon called by some authors as non-protective monogamy. On the other hand, young university students use lesser the condom under the effects of substances, as observed by Ballester et al. (2009) or Castro (2016) in Spain and Bellis et al. (2008) in rest of Europe. More than half of unsafe sexual practices happen under the influence of alcohol. These substances increase sexual relations because of their effect on disinhibition, and affect the use of condoms because of their effect on cognitive functions such as decision making, judgment and reasoning.

Information and formation about risk prevention is not enough to engage in safe behaviors. Some authors such as Ballester-Arnal et al. (2017), Castro (2016), Davis et al. (2014), MacDonald et al. (2016) and Rodrigues et al. (2019) suggest that individual or contextual differences may be considered factors to improve the effectiveness of preventive strategies. In our study, sexual sensation seeking has been the main 
explanatory factor of the inconsistent use of condoms in different sexual contexts. However, it entails a low increase likelihood of engaging in risky sexual behaviors. Perhaps the age of the participants has influenced the results obtained because, as Romer and Hennessy (2007) described, this trait nears a lifetime peak during late adolescence and early adulthood. The association between this trait and risky sexual behaviors has been demonstrated in university students by Gullette and Lyons (2005) or more recently by Gil-Llario et al. (2016). Young university students are driven by sexual stimulation and experience, prioritize the sensual and physical aspects of the sexual encounter, over the cognitive aspects necessary to make a decision to use the condom. Although biological studies have related this trait as characteristic associated to male sex, in our study appears that it plays a fundamental role in explaining sexual behavioral also in females. These results could suggest the importance of socialization in the development of seeking sexual sensations, as Davis et al. (2014) argued.

On the other hand, influence of differential psychological traits have been found according to gender and the sexual situation evaluated, according to studies by Muñoz-Silva et al. (2009) or Vianello et al. (2013).

In young women, self-esteem has appeared as a risk factor in sexual intercourses with a steady partner. This result confirms the "dark side" that Brendgen et al. (2004) observed to self-esteem as a risk mediator of externalizing problems. It is possible that feelings positive emotions towards oneself influences the overestimation of one's social competence to assess risks. In addition, extraversion has appeared as a protective factor in sexual intercourses under the substance use, perhaps because the predisposition to interpersonal and socialization skills could influence the greater sexual assertiveness, for example competence to discuss or negotiate the use of condoms.

In young men, neuroticism has appeared as a protective factor in sexual intercourses with a steady partner. The tendency to experience negative emotions can increase the sensation of vulnerability and, therefore, it is possible that they engage in safe behaviors for preventing negative emotions as Sarno et al. (2017) suggested. However, fear of negative evaluation has appeared as a risk factor in sexual intercourse under substance use. In this sense, substances may be used as a mechanism of emotional self-regulation, the effects of which interfere with condom use skills as it appeared in the study by Hart and Heimberg (2005).

This study has some limitations such as sample size, which could be enlarged, o the inclusion of young people with sexual orientations non-heterosexual. On the other hand, the use of a self-report with response alternatives as a method of collecting the information of the criterion variable, does not allow to examine in depth the complexity of the condom use behavior, use qualitative tools such as interviews or focus group would be complementary. Finally, the methodological decision to dichotomize the groups has been able to influence the results. In this study, a strict criterion of risk of infection has been taken. Therefore, only the consistent use of condoms ensures HIV prevention. However, it would be interesting to analyze what psychological factors would appear involved in the different frequencies of condom use and if there are contextual factors associated.

The results show that having higher education or belonging to an educational segment of population with great opportunities to acquire knowledge does not protect against risky sexual behaviors. University students are a majority group between young people in Spain and nowadays they are still a group at risk. The university, therefore, can be an optimal environment to provide education for sexual health from a transversal focus. However, it is necessary to know the psychological mechanisms that underlie sexual risk behaviors for adapting interventions to individual and contextual characteristics. For this reason, preventive measures have to incorporate the gender perspective and the diversity of types of sexual relationships that young people maintain. 


\section{References}

Área de Vigilancia de VIH y Comportamientos de Riesgo (2018). Vigilancia epidemiológica del VIH y Sida e n España 2017: Sistema de información sobre nuevos diagnósticos de VIH y Registro Nacional de Casos de Sida [Epidemiological Surveillance of HIV and AIDS in Spain 2017: Information System on New HIV Di agnoses and National Registry of AIDS Cases]. https://www.mscbs.gob.es/ciudadanos/enfLesiones/enfTr ansmisibles/sida/vigilancia/doc/InformeVIH_SIDA_2018_21112018.pdf

Ballester, R., Gil, M. D., Giménez, C., \& Ruiz, E. (2009). Actitudes y conductas sexuales de riesgo para la in fección por VIH/SIDA en jóvenes españoles [Attitudes and sexual behaviors of risk for HIVIAIDS infection in Spanish youth]. Revista de Psicopatología y Psicología Clínica, 14(3), 181-191. https://doi.org/10.594 4/rppc.vol.14.num.3.2009.4077

Ballester-Arnal, R., Gil-Llario, M. D., Ruiz-Palomino, E., \& Giménez-García, C. (2013). Autoeficacia en la pr evención sexual del Sida: La influencia del género [Self-efficacy in AIDS sexual prevention: Influence of $\mathrm{g}$ ender]. Anales de Psicología/Annals of Psychology, 29(1), 76-82. http://doi.org/10.6018/analesps.29.1.12 4601

Ballester-Arnal, R., Gómez-Martínez, S., Gil-Llario, M. D., \& Salmerón-Sánchez, P. (2013). Sexual Compulsi vity Scale: Adaptation and validation in the Spanish population. Journal of Sex \& Marital Therapy, 39(6), 5 26-540. http://doi.org/10.1080/0092623X.2012.665816

Ballester-Arnal, R., Ruiz-Palomino, E., \& Gil-Llario, M. D. (2017). Structural equation modeling test of an int egrated model of Spanish youth's condom use. AIDS \& Behavior, 21(5), 1407-1416. http://doi.org/10.100 7/s10461-016-1430-x

Ballester-Arnal, R., Ruiz-Palomino, E., Espada-Sánchez, J. P., Morell-Mengual, V., \& Gil-Llario, M. D. (201 8). Psychometric properties and validation of the Sexual Sensation Seeking Scale in Spanish adolescent s: Brief screening method for use in research and clinical practice. Personality and Individual Differences, 122, 47-54. https://doi.org/10.1016/j.paid.2017.10.006

Bellis, M. A., Hughes, K., Calafat, A., Juan, M., Ramon, A., Rodriguez, J. A., Mendes, F., Schnitzer, S., \& Ph illips-Howard, P. (2008). Sexual uses of alcohol and drugs and the associated health risks: A cross sectio nal study of young people in nine European cities. BMC Public Health, 8(1), Article 155. http://doi.org/10.1 186/1471-2458-8-155

Brendgen, M., Vitaro, F., Turgeon, L., Poulin, F., \& Wanner, B. (2004). Is there a dark side of positive illusion s? Overestimation of social competence and subsequent adjustment in aggressive and nonaggressive chi Idren. Journal of Abnormal Child Psychology, 32, 305-320. http://doi.org/10.1023/B:JACP.0000026144.08 470.cd

Castañeiras Gebrikian, C. E. (2001). Avances en Psicopatologia y Clinica de la hipocondría [Advances in P sychopathology and Clinical of the Hypochondria] (Unpublished doctoral dissertation). Universidad de Val encia, Valencia, Spain.

Castro, Á. (2016). Sexual behavior and sexual risks among Spanish university students: A descriptive study of gender and sexual orientation. Sexuality Research and Social Policy, 13(1), 84-94. https://doi.org/10.1 007/s13178-015-0210-0

Cordero, A., Pamos, A., \& Seisdedos, N. (2008). NEO PI-R Manual. Adaptación Española [Revised NEO P ersonality Inventory (NEO PI-R) manual. Spanish Adaptation] ( $3^{\text {th }}$ Ed.). TEA Ediciones.

Davis, K. C., Stappenbeck, C. A., Norris, J., George, W. H., Jacques-Tiura, A. J., Schraufnagel, T. J., \& Kaju mulo, K. F. (2014). Young men's condom use resistance tactics: A latent profile analysis. The Journal of $S$ 
ex Research, 51(4), 454-465. http://doi.org/10.1080/00224499.2013.776660

European Centre for Disease Prevention and Control (2018). HIVIAIDS surveillance in Europe 2018-2017d ata. http://www.euro.who.int/_data/assets/pdf_file/0004/386959/HIVAIDS-surveillance-in-Europe-2018.p df?ua=1

European Centre for Disease Prevention and Control (2019a). Chlamydia infection. Annual epidemiological report for 2017. https://www.ecdc.europa.eu/sites/default/files/documents/AER_for_2017-chlamydia-infect ion.pdf

European Centre for Disease Prevention and Control (2019b). Gonorrhea. Annual epidemiological report for 2017. https://www.ecdc.europa.eu/sites/default/files/documents/gonorrhoea-annual-epidemiological-repor t-2017.pdf

European Centre for Disease Prevention and Control (2019c). Syphilis. Annual epidemiological report for 20 17. https://www.ecdc.europa.eu/sites/default/files/documents/syphilis-annual-epidemiological-report-201 7.pdf

Gallego, M. J. (2010). Brief version of the Fear of Negative Evaluation Scale - Straightforward items (BFNES): Psychometric properties in a Spanish population. The Spanish Journal of Psychology, 13(2), 981- 98 9. https://doi.org/10.1017/S1138741600002626

Gil-Llario, M. D., Ruiz-Palomino, E., Ballester-Arnal, R., \& Morell-Mengual, V. (2016). Influence of sexual se nsation seeking, sexual compulsivity and sexual pleasure in condom use among Spanish youth: Implicati ons for HIV interventions. Journal of Preventive Medicine and Care, 1(3), 1-8. http://doi.org/10.14302/iss n.2474-3585.jpmc-16-1198

Gil-Llario, M. D., Ruiz-Palomino, E., Morell-Mengual, V., Giménez-García, C., \& Ballester-Arnal, R. (2019). Validation of the AIDS Prevention Questionnaire: A brief self-report instrument to assess risk of HIV infecti on and guide behavioral change. AIDS \& Behavior, 23(1), 272-282. http://doi.org/10.1007/s10461-018-22 24-0

Gullette, D. L., \& Lyons, M. A. (2005). Sexual sensation seeking, compulsivity, and HIV risk behaviors in coll ege students. Journal of Community Health Nursing, 22(1), 47-60. http://doi.org/10.1207/s15327655jchn2 201_5

Hart, T. A., \& Heimberg, R. G. (2005). Social anxiety as a risk factor for unprotected intercourse among gay and bisexual male youth. AIDS \& Behavior, 9(4), 505-512. http://doi.org/10.1007/s10461-005-9021-2

Instituto Nacional de Estadística (2003). Encuesta de salud y hábitos sexuales. Informe general [The Spani sh National Sexual Health Survey. General report]. https://www.ine.es/ss/Satellite?L=es_ES\&c=INEPublic acion_C\&cid=1259924965002\&p=1254735110672\&pagename=ProductosYServicios\%2FPYSLayout $\mid m$ 1=PYSDetalleGratuitas

Lameiras Fernández, M., Faílde Garrido, J. M., Bimbela Pedrola, J. L., \& Alfaro Oliver, N. (2008). Uso del pr eservativo masculino en las relaciones con coito vaginal de jóvenes españoles entre catorce y veinticuatr o años [Use of the male condom in relations with vaginal intercourse of young Spaniards between fourtee n and twenty-four years]. Diversitas: Perspectivas en Psicología, 4(2), 401-415.

Luengo-Arjona, P., Orts-Cortés, M. I., Caparrós-González, R. A., \& Arroyo-Rubio, O. I. (2007). Comportamie nto sexual, prácticas de riesgo y anticoncepción en jóvenes universitarios de Alicante [Sexual behavior, u nsafe prácticas and contracepction in students attending Alicante University (Spain)]. Enfermería Clínica, 17(2), 85-89. http://doi.org/10.1016/S1130-8621(07)71774-6

MacDonald, T. K., McKenna, C., \& Mouck, L. C. (2016). The person and the partner: Individual differences moderate the relationship between partner feedback and condom use. AIDS \& Behavior, 20, 185-196. htt 
p://doi.org/10.1007/s10461-015-1153-4

Martín-Albo, J., Núñez, J. L., Navarro, J. G., \& Grijalvo, F. (2007). The Rosenberg Self-Esteem Scale: Trans lation and validation in university students. The Spanish Journal of Psychology, 10(2), 458-467. https://do i.org/10.1017/S1138741600006727

Ministerio de Sanidad, Consumo y Bienestar Social (2017). Interrupción voluntaria del embarazo. Datos defi nitivos correspondientes al año 2017 [Voluntary interruption of pregnancy. Final data for 2017]. https://ww w.mscbs.gob.es/profesionales/saludPublica/prevPromocion/embarazo/docs/IVE_2017.pdf

Muñoz-Silva, A., Sánchez-García, M., Martins, A., \& Nunes, C. (2009). Gender differences in HIV-related se xual behavior among college students from Spain and Portugal. The Spanish Journal of Psychology, 1 2(2), 485-495. https://doi.org/10.1017/S1138741600001864

Prat, F., Planes, M., Gras, M. E., \& Sullman, M. J. M. (2016). Perceived pros and cons of condom use as pr edictors of its consistent use with a heterosexual romantic partner among young adults. Current Psycholo gy, 35, 13-21. http://doi.org/10.1007/s12144-015-9357-3

Rojas-Murcia, C., Pastor, Y., \& Esteban-Hernández, J. (2015). Ilusión de invulnerabilidad, estereotipos y per cepción de control del SIDA en universitarios [Illusion of invulnerability, stereotypes and perception of con trol to AIDS in undergraduate students]. Revista Iberoamericana de Psicología y Salud, 6(1), 28-38. htt p://doi.org/10.1016/S2171-2069(15)70004-9

Rodrigues, D. L., Prada, M., \& Lopes, D. (2019). Perceived sexual self-control and condom use with primary and casual sex partners: Age and relationship agreement differences in a Portuguese sample. Psycholog $y$ \& Health, 34(10), 1231-1249. http://doi.org/10.1080/08870446.2019.1603384

Romer, D., \& Hennessy, M. (2007). A biosocial-affect model of adolescent sensation seeking: The role of aff ect evaluation and peer-group influence in adolescent drug use. Prevention Science, 8, 89-101. http://do i.org/10.1007/s11121-007-0064-7

Sánchez-Ojeda, M. A., \& Luna-Bertos, E. D. (2015). Hábitos de vida saludable en la población universitaria [Healthy lifestyles of the university population]. Nutrición Hospitalaria, 31(5), 1910-1919. http://doi.org/1 0.3305/nh.2015.31.5.8608

Sanz, J., Navarro, M. E., \& Vázquez, C. (2003). Adaptación española del Inventario para la Depresión de B eck II (BDI-II): Propiedades psicométricas en estudiantes universitarios [The Spanish adaptation of Bec k's Depression Inventory-II (BDI-II): 2. Psychometric properties in university students]. Análisis y Modific ación de Conducta, 29(124), 239-288.

Sarno, E. L., Mohr, J. J., \& Rosenberger, J.G. (2017). Affect and condom use among men who have sex wit h men: A daily diary study. AIDS \& Behavior, 21, 1429-1443. http://doi.org/10.1007/s10461-016-1464-0

Ssewanyana, D., Sebena, R., Petkeviciene, J., Lukács, A., Miovsky, M., \& Stock, C. (2015). Condom use in the context of romantic relationships: A study among university students from 12 universities in four Centr al and Eastern European countries. The European Journal of Contraception \& Reproductive Health Care, 20(5), 350-360. http://doi.org/10.3109/13625187.2014.1001024

Unidad de Vigilancia del VIH y Conductas de Riesgo (2019). Vigilancia epidemiológica de las infecciones d e transmisión sexual, 2017 [Epidemiological surveillance of sexually transmitted infections, 2017]. http s://www.mscbs.gob.es/ciudadanos/enfLesiones/enfTransmisibles/sida/vigilancia/Vigilancia_ITS_1995_20 17_def.pdf

Velo-Higueras, C., Cuéllar-Flores, I., Sainz-Costa, T., Navarro-Gómez, M. L., García-Navarro, C., Fernánde z-McPhee, C., Ramírez, A., Bisbal, O., Blazquez-Gamero, D., Ramos-Amador, J. T., Valencia-Ortega, E., \& González-Tomé, I. (2019). Jóvenes y VIH. Conocimiento y conductas de riesgo de un grupo residente e 
n España [Young people and HIV. Knowledge and risk behaviors in a group of residents in Spain]. Enferm edades Infecciosas y Microbiología Clínica, 37(3), 176-182. http://doi.org/10.1016/j.eimc.2018.05.015

Vianello, M., Schnabel, K., Sriram, N., \& Nosek, B. (2013). Gender differences in implicit and explicit person ality traits. Personality and Individual Differences, 55(8), 994-999. https://doi.org/10.1016/j.paid.2013.08.0 08

Wallston, B. S., Wallston, K. A., Kaplan, G. D., \& Maides, S. A. (1976). Development and validation of the $h$ ealth locus of control (HLC) scale. Journal of Consulting and Clinical Psychology, 44(4), 580. https://doi.or $\mathrm{g} / 10.1037 / 0022-006 X .44 .4 .580$

World Health Organization (2019). European Health Information Gateway: Data of number of abortions. http s://gateway.euro.who.int/en/indicators/hfa_587-7011-number-of-abortions-all-ages/visualizations/\#id=206 $45 \&$ tab $=$ table 